\title{
A INTENÇÃO PANKARARU: \\ A "DANÇA DOS PRAIÁS" COMO TRADUÇÃO INTERCULTURAL NA CIDADE \\ DE SÃO PAULO
}

\begin{abstract}
Marcos Alexandre dos Santos Albuquerque ${ }^{1}$
\section{Introdução - Tradução como Interculturalidade ${ }^{2}$}

"O real não está na saída nem na chegada: ele se dispõe para a gente é no meio da travessia” (Guimarães Rosa)
\end{abstract}

A expansão dos modelos político-culturais do ocidente (o Estado, o colonialismo, o capitalismo global e outros) não foi capaz de extinguir as populações nativas. Ao contrário do que se previa, tais comunidades têm protagonizado estratégias políticas e culturais que veem fornecendo à antropologia novos desafios e objetos de investigação. Como escreveu Néstor García Canclini (2005: 24), os grandes avanços da antropologia decorrem do fato desta disciplina "ter sabido situar-se na interação entre culturas". Para Canclini, autores como Marc Abélès, Arjun Appadurai e James Clifford entre outros, estão renovando a disciplina ao redefinir a noção de cultura e concebê-la como um sistema de relações de sentido que identifica diferenças, contrastes e comparações ${ }^{3}$.

Trata-se, este é o ponto, de "prestar atenção às misturas e aos mal-entendidos que vinculam os grupos" (ibid.: 25) ao invés de descrever a "cultura" como consenso e identidade. Como parte deste movimento, se tornou cada vez mais razoável na antropologia a apropriação de termos e do método de outras disciplinas para falar de um objeto que tradicionalmente lhe era reservado. De forma mais incisiva, Canclini escreveu que "num tempo de globalização, o objeto mais revelador, mais questionador das pseudo-certezas

\footnotetext{
${ }^{1}$ Universidade do Estado do Rio de Janeiro (UERJ), Brasil.

${ }^{2}$ Artigo originalmente publicado na Revista Cadernos do LEME (v. 2, p. 2-33, 2010) da UFCG.

${ }^{3}$ Por exemplo, as pesquisas que estão no campo de investigação das redes (Marcus, 1998; Gell, 1998; Latour, 2005), dos sistemas globais (Appadurai, 1994), dos híbridos (Latour, 1994; Hannerz, 1997), das traduções interculturais (Taussig, 1993; Bhabha, 1998), da propriedade e das autenticidades culturais (Handler\&Linnekin, 1984; Clifford, 1999; Marcus \& Fischer, 2000; Price, 2000; Golçalves, 2002).
} 
etnocêntricas ou disciplinares é a interculturalidade. [...] Estudar a cultura requer, então, converter-se em especialista das interações" (ibid.).

O conceito de interculturalidade se contrapõe ao usual multiculturalismo, pois para Canclini o multiculturalismo reconhece strito senso a existência de diferentes identidades culturais. O conceito de interculturalidade pressupõe que a diferença cultural é construída no próprio jogo do poder através das estratégias de composição de patrimônios culturais, de negociações da autenticidade entre o tradicional e o moderno, da constituição de híbridos, sincréticos, simulacros dentre outros. Com interculturalidade o autor quer "examinar sob que condições se administram as diferenças, as desigualdades, a inclusão-exclusão e os dispositivos de exploração em processos interculturais" (ibid.: 53).

A partir do conceito de interculturalidade, esse artigo descreve o processo social de constituição de um sinal diacrítico por uma população indígena no contexto de uma metrópole brasileira. Desde 1940 os Pankararu migram de suas aldeias em Pernambuco para a cidade de São Paulo, hoje somam mais de 2000 pessoas nessa cidade. Em 1994 eles fundaram uma associação como forma de reivindicar direitos e passaram a realizar apresentações de uma performance, a “dança dos praiás”. Essa performance se constitui em uma versão heterodoxa de uma dança ritual restrita às suas aldeias em Pernambuco. Tendo em vista que a gênese dessa performance encontra-se no contexto, político e ritual, da interseção de atores sociais assimetricamente dispostos no campo do poder (político, econômico, simbólico e outros), essa performance será analisada como um projeto nativo intercultural contra hegemônico, cuja intenção é dotar os Pankararu de capital simbólico na cidade de São Paulo.

Desse modo, analiticamente proponho pensar essa performance como uma forma de tradução. Considerando que todo elemento cultural tem uma história particular, para entendê-los devemos demarcar as categorias e as experiências que constituem essa historicidade. Portanto, essa performance é uma tradução porque, como escreveu Homi Bhabha (1998: 20-21),

A representação da diferença não deve ser lida apressadamente como o reflexo de traços culturais ou étnicos preestabelecidos, inscritos na lápide fixa da tradição. A articulação social da diferença, da perspectiva da minoria, é uma negociação complexa, em andamento, que procura conferir autoridade aos hibridismos culturais que emergem em momentos de transformação histórica. 
Nesse sentido, o discurso contra hegemônico das minorias comporta muito bem a ideia do novo como ato insurgente de "tradução cultural" (ibid.: 27). Tradução que "não apenas retoma o passado como causa social ou precedente estético; ela renova o passado, reconfigurando-o como um 'entre-lugar' contingente, que inova e irrompe a atuação do presente". É nesse sentido que as traduções constituem-se tanto como o espaço ideal dos espelhamentos, do consenso e do multiculturalismo, como, inversamente, o espaço pragmático das contra-hegemonias, das ironias, e da interculturalidade.

Ao invés do apelo de uma tradução ideal, uma tradução como pragmática enfatiza o fato de que o ato de traduzir está renunciando a ser ideal e revela suas próprias intenções. Nos termos de Benjamim (2008: 35), a intenção da tradução "não é somente dirigida a finalidades diferentes mas difere já em si própria da intenção da obra original: enquanto a intenção da obra artística é ingênua, primária e plástica, a tradução norteia-se por uma intenção já derivada, derradeira mesmo e feita de ideias abstratas". A tradução deve, portanto, ser pensada como uma agência, um ato social em diálogo, cujos conteúdos (políticos, rituais e outros) procuram constituir a identidade pela diferença. Uma tradução será bem sucedida somente se renunciar ao estigma de não ser o original e, portanto, revelar-se tradução, cujas intenções derivadas, pragmáticas e abstratas (no sentido de discurso) têm de ser levadas em conta em função do processo de interculturalidade que constitui a imagem da diferença hoje.

A seguir procuro demonstrar a operacionalidade dessa categoria (tradução intercultural) a partir da análise de uma situação social específica analisada em minha pesquisa de doutorado em antropologia social no PPGAS/UFSC. Trata-se de apresentar a performance "dança dos praiás" como uma tradução intercultural, constituída pelos Pankararu de forma a permitir sua visibilidade social em arenas da cidade de São Paulo. Faço isso em três momentos. No primeiro apresento a diáspora Pankararu como o resultado do poder tutelar e a "autenticidade" do grupo, nas arenas de São Paulo, como a atualização desse poder. No segundo apresento os termos da tradução realizada pelos Pankararu ao contrastar a "dança" dos praiás (realizada nos terreiros das aldeias Pankararu em Pernambuco), com a "dança dos praiás" (realizada nas arenas de São Paulo). E ainda, defino o ato Pankararu de tradução, sua intenção, como um ato político cuja autenticidade, do ponto de vista nativo, é ratificada cotidianamente pelo ato ritual que atualiza o político. 
Por fim, demonstrarei que o ato político e o ritual formam um único e mesmo ato contrahegemônico de tradução intercultural, cuja intenção é vencer a violência simbólica que tende a atualizar categorias do poder tutelar e, portanto, invisibilizar os Pankararu como uma comunidade etnicamente diferenciada em São Paulo.

\section{Poder tutelar, diáspora e a autenticidade Pankararu nas arenas de São Paulo}

Seguindo teoricamente uma antropologia histórica (Oliveira, 1988; 1999a), a população chamada hoje de Pankararu ${ }^{4}$ foi formada pelo aldeamento de diversos grupos nativos e, posteriormente, de ex-escravos, que habitavam a região do sub-médio do vale do São Francisco no estado de Pernambuco, nordeste do Brasil, durante a formação do país. Somente no ano de 1940 os Pankararu apareceram como grupo indígena nos quadros administrativos do governo ao conseguirem o reconhecimento dessa identidade e a regularização de seu território tradicional (finalmente regularizado em 1996). Um importante elemento de reconhecimento dessa comunidade como indígenas foi o fato de que nela se realizavam uma série de rituais cujas características culturais atestavam, aos olhos do órgão público da época (o Serviço de Proteção ao Índio - SPI), a origem autóctone do grupo, admitindo-os, portanto, no quadro de comunidades assistidas pelo órgão tutor.

Como bem demonstrou Souza Lima (1995), a categoria de índio (ou indígena) foi instituída pelo aparelho administrativo do estado brasileiro como uma nomenclatura geral para representar o conjunto de povos nativos do território brasileiro. Historicamente essa "presença" de povos nativos no território brasileiro foi considerada uma grave "questão" nacional. Intitulada de a "questão indígena", sinteticamente, ela significa o problema político e jurídico do lugar dos povos nativos na formação do Brasil. O percurso histórico dos modelos de gestão desse problema/“questão" foram, primeiro, durante o período imperial, o da "guerra como política", e, com o advento da republica, passou a ser o da "política como guerra". É nesse momento que se institui um tipo muito específico de dispositivo político-administrativo, o poder tutelar (ibid.).

\footnotetext{
${ }^{4}$ O nome místico do grupo é Pancarú Geritacó Cacalancó Umã Canabrava Tatuxi de Fulô.
} 
O poder tutelar fazendo a "paz" atualiza, de maneira diferente, a "guerra de conquista", isso porque no exercício do poder tutelar a violência aberta do período imperial se transforma em violência simbólica no período republicano. O poder tutelar se constitui num dispositivo disciplinar do estado brasileiro cujo exercício implica no monopólio de definição e controle sobre a população ao qual incide, instituindo para tanto uma definição extra nativa do ser indígena como parte de dispositivos de poder, momento em que se desloca o direito à identidade para uma forma externa de atribuição. Sob a administração desse poder tutelar, os povos nativos foram classificados em estágios de "aculturação" que se tornaram marcadores da integração dessa população ao exercício econômico da sociedade brasileira como um todo (ibid.).

Naturalizando assim a violência colonialista ao classificar (o suposto no lugar do imposto) os povos indígenas em "graus" de "assimilação", essa forma de atribuição externa instituiu um instrumento de controle e invisibilização dos povos autóctones. Definidos e classificados de tal maneira, ao estado cabia a tarefa de construir mecanismos administrativos que promovessem a extinção gradual das afinidades étnicas e dos laços de solidariedade entre os povos nativos, permitindo assim a "assimilação" dessas populações ao grosso da população chamada de "brasileira" (ibid.).

Desse ponto de vista, os "territórios indígenas" são parte e categoria do quadro administrativo do Estado no processo geral de regularização econômica e fundiária do país. Ao isolar os povos nativos em aldeias procurava-se apaziguar os conflitos que ocorriam no campo pelo domínio de território entre nativos e colonizador. Além disso, sedentarizando povos errantes, o poder tutelar pretendia vencer, pela "não violência", a resistência dos povos nativos em se fixarem em lugares definidos pelo Estado (ibid.). Com a imposição da imobilidade aos povos nativos, o Estado pode conter e vigiar essa população a fim de transformá-la, gradualmente em trabalhadores rurais e garantir, assim, a ocupação do campo e a disponibilização de mão de obra para essas regiões.

$\mathrm{Na}$ medida em que as aldeias tinham tamanhos reduzidos, que fronteiras foram instituídas, proibindo-se a entrada em locais que antes eram espaços de coleta, de caça e sobrevivência material e cultural, a soma das más condições nas aldeias exigiu dos indígenas que migrassem a procura de trabalho nas fazendas e pequenas cidades no entorno das aldeias. Esse processo favoreceu a inserção desses grupos na população pobre do 
campo e das pequenas cidades tornando esses indígenas invisíveis e ilegítimos no momento em que categorias próprias do poder tutelar ("aculturado", "assimilado", e outras) ganham o campo do discurso da sociedade como um todo.

Tais categorias, portanto, são hoje de uso franco no discurso preconceituoso, estigmatizante e ideológico que setores da sociedade brasileira insistem em manter com relação à representação dos povos nativos. Tal representação, paradigmaticamente, regida pelo modelo do "museu" (ver adiante), evoca a "primitividade", a "pobreza", a atemporalidade e o anonimato, como condição de autenticidade das culturas nativas. Instituindo assim, de forma arbitrária, a "cultura nativa" como estática, tanto no tempo histórico quanto no espaço físico (co-extensiva a um território específico), cuja sobrevivência fora do tempo (história) e do espaço (suas fronteiras), conveniência das conveniências, está garantida pelo "museu". Portanto, categorias do poder tutelar, como as de "desaldeados", "aculturados" e outras serviram, e são atualizadas ainda hoje, como dispositivos para retirar do indígena a sua permanência no campo da história e invisibilizar sua presença fora das Terras Indígenas (TI`s).

O Instituto Brasileiro de Geografia e Estatística (IBGE) realizou em 2000 o Censo PNAD (Pesquisa Nacional por Amostragem de Domicílios), o censo da população brasileira. Nos resultados desse censo constatou-se o total de 734 mil indígenas, sendo que 383.298 destas vivem em cidades, e 350 mil em áreas rurais. Esses números passaram a apresentar uma nova realidade da distribuição da população indígena no país, agora 52,21\% da população indígena encontra-se nas regiões urbanas, sendo que dos vinte municípios com maior numero de habitantes indígenas, dez são capitais. Isso mostra que a realidade do indígena que está no meio urbano é significativamente o contexto das grandes cidades. Mas não para a FUNAI, que ainda trabalha com o numero de 350 mil indígenas no Brasil, numero esse que representa quase que apenas a população indígena que é atendida pelo órgão em TI’s, e cuja legislação é extremamente ambígua com relação a população que está nas cidades. 
É nesse contexto que o número de indígenas vivendo na região metropolitana de São Paulo veio aumentando a cada censo. Em 1998 o IBGE havia registrado 33.829 indígenas, em 2000 esse número foi de 59.989, constituindo a terceira maior população indígena do país (atrás somente dos estados da Amazônia, 113.391 e Bahia, 64.240) ${ }^{5}$. No entanto, no último registro realizado pela FUNASA (2007), órgão público responsável pela saúde dos povos indígenas, existiam pouco mais de duas mil pessoas cadastradas, ou seja, apenas 3,6\% da população indígena migrante que vive na região metropolitana de São Paulo tinha algum tipo de atendimento diferenciado no sistema de saúde ${ }^{6}$. Desses pouco mais de 2000, 1338 eram da etnia Pankararu, pelos dados da FUNASA (e outros, como CIMI, ONG "Opção Brasil") as principais etnias que constituem a população indígena migrante da cidade de São Paulo são do nordeste brasileiro, com enorme destaque para os Pankararu.

A disparidade entre dados do CENSO e os dados da FUNASA mostra como os indígenas em São Paulo têm dificuldade em terem seus direitos efetivados. O principal instrumento de contestação da "autenticidade" dos indígenas, seja do poder publico de forma ampla (FUNAI, FUNASA, e outros), que os mantêm, administrativamente num "limbo jurídico", seja a própria sociedade civil que os estereotipa, vem da atualização de categorias do poder tutelar e contemporização com o "senso comum" ${ }^{7}$. Noções como "desaldeado" são recorrentemente colocadas como obstáculo pelo poder público para que a população indígena migrante consiga regularizar o acesso a direitos, reivindicando um "limbo jurídico" (a falta de instrumentos jurídicos e administrativos que discriminem a

\footnotetext{
${ }^{5}$ Pelo levantamento da ONG Opção Brasil, realizado pela equipe do Projeto "Índios na Cidade" e atualizado em maio de 2009, as etnias existentes na Grande SP são 51: Aranã, Atikum, Baniwa, Cinta Larga, Fulni-ô, Geripankó, Guajajara, Guarani Kaiowá, Guarani Mby’a, Guarani Nhamdeva, Kaingang, Kaimbé, Kalapalo, Kambiwá, Kamayurá, Kanela, Kantaruré, Kapinawá, Karajá, Kariri, Kariri-Xocó, Katokim, Kaxinawá, Kayabi, Pankararé, Kayapó, Krenak, La Klãnõ, Macuxi, Munduruku, Mura, Nhambiquara, Pankararu, Pataxó, Pataxó HãHãHãe, Potiguara, Puri, Tapeba, Terena, Ticuna, Tremembé, Truká, Tukano, Tuxá, Tuyuka, Wassu, Xavante, Xerente, Xukuru, Xukuru-Kariri e Yanomami.

${ }^{6}$ Tabela com os dados cadastrais da FUNASA, número de indígenas por etnia: Atikum $=25 ;$ Kambiwa $=10$; Terena $=34$; FULNI-ô $=18$; Katokin $=2$; Tuxa $=3$; Pankarare $=302$; Wassu $=25$; Guajajara $=1$; Pankararu $=1338 ;$ Xukuru $=106 ;$ Jeripankó $=1 ;$ Pataxo $=9 ;$ Xukuru-Kariri $=1 ;$ Kaimbé $=2$; Potyguara $=28$.Essa tabela não conta a população guarani das quatro aldeias da grande SP.

${ }^{7}$ Como muito bem definiu e apontou Oliveira (1999b: 176), o antropólogo deve, "evitar contemporizações, explicitando que considera e reconhece como sociedade indígena toda aquela coletividade que por suas categorias e circuitos de interação se distingue da sociedade nacional, e se reivindica como 'indígena', isto é, descendente - não importa se em termos genealógicos, históricos ou simbólicos - de uma população de origem pré-colombiana”.
} 
forma de atuação do poder publico junto a essas comunidades) o poder público atualiza a violência simbólica da "política como guerra" do poder tutelar cujo resultado prático é a manutenção da invisibilidade dos indígenas no contexto urbano e a constituição de uma omissão legítima ${ }^{8}$.

É nesse contexto que os Pankararu surgem como uma população indígena migrante, "desaldeada" e "aculturada" aos olhos do poder publico e da sociedade paulistana nos anos 1990. A migração vivida por esse grupo foi definida como uma diáspora (Arruti, 1999).

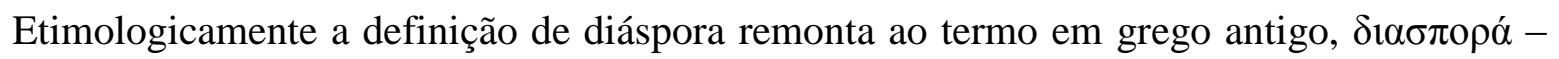
"dispersão", que se define como o deslocamento, normalmente forçado ou incentivado, por motivos religiosos ou políticos, de comunidades ou populações originárias de uma região para outras. A diáspora Pankararu para São Paulo começou nos anos 1940 e se intensificou nas duas décadas seguintes. Em São Paulo os primeiros Pankararu que chegaram não tinham instrução formal e tornaram-se trabalhadores braçais. A maioria trabalhava nas equipes de desmatamento da Cia. De Luz do Estado para onde eram agenciados por "gatos" que iam buscá-los na própria aldeia, para entregá-los em lotes, ao "empreiteiro" das obras (Arruti, 1999: 267).

Uma boa parte dos Pankararu trabalhou naconstrução do estádio de futebol Cícero Pompeu de Toledo (o Estádio do Morumbi). Próximo ao local dos alojamentos, alguns trabalhadores começaram a se apossar de partes do terreno às margens do rio Pinheiros que eram de utilidade publica, "sobras" do loteamento do bairro e destinadas a construção de benfeitorias públicas que nunca chegaram a termo, formando assim uma "favela", inicialmente chamada de "favela da mandioca" e posteriormente com o nome do bairro, "favela do Real Parque". Foi nesse contexto que grande número de Pankararu acabou construindo um endereço fixo em São Paulo o que possibilitou a vinda de parentes formando assim uma migração constante para São Paulo, normalmente intercalada entre grandes períodos de trabalho em São Paulo e breves retornos a aldeia em Pernambuco. O

\footnotetext{
${ }^{8}$ O Supremo Tribunal Federal brasileiro declarou que a regra constitucional não "pode converter-se em promessa constitucional inconsequente, sob pena de o Poder Público, fraudando justas expectativas nele depositadas pela coletividade, substituir, de maneira ilegítima, o cumprimento de seu impostergável dever, por um gesto irresponsável de infidelidade governamental ao que determina a própria Lei Fundamental" (AgRg RE 393715/RS, Rel. Min. Celso de Mello, 2a Turma, julg. 12/12/2006, DJ 02-02-2007, p. 140.).
} 
número de Pankararu em São Paulo gira em torno de 2000 pessoas e na favela do Real Parque estão pelo menos 1/4 da população Pankararu da cidade.

O núcleo Pankararu que se formou na "favela do Real Parque" começou a ganhar visibilidade social a partir do incremento da política de autogestão e associativismo que caracterizou os movimentos sociais pós Constituição de 1988. Como não existe um mecanismo jurídico específico de reconhecimento dos indígenas migrantes, os Pankararu do Real Parque, inseridos numa gama de entidades de assistência eclesial, de ONGs e de associações auto gestionadas, lançaram mão da experiência com o associativismo vindo do cotidiano da favela e também do contato com outros povos indígenas ${ }^{9}$. Assim, em 1992, formaram sua primeira associação, a SOS Índios Favelados, depois, em 1994, renomeada de Associação Indígena Comunidade Indígena Pankararu, a SOS-CIP, entidade que formalmente representa os Pankararu em São Paulo junto a FUNAI, FUNASA e outros órgão públicos e entidades da sociedade civil.

Ao se inserirem em campos de atuação política e ganharem alguma visibilidade social, os Pankararu passaram a se inserir em circuitos conexos aos espaços de mobilização social e demandas simbólicas começaram a surgir, no caso, demandas por sinais diacríticos capazes de "provar" a legitimar das demandas políticas e étnicas dos Pankararu. Solicitados a exibir traços culturais que os qualificasse como uma população diferenciada, mesmo que em contexto urbano, os Pankararu constituíram a performance "dança dos praiás".

Ao constituírem uma associação, os Pankararu do Real Parque constituíram duplamente uma forma de se representarem politicamente como comunidade e, também, uma forma de se representarem simbolicamente como indígenas. Esse duplo percurso não esteve separado e nem se conformou como uma caminhada em separado. Ao incrementarem sua presença política em espaços de mobilização social os Pankararu foram, ao longo do tempo, desenvolvendo uma atividade simbólica e cultural que tinha por objetivo constituir uma resposta a demanda por sinais diacríticos e por autenticidade cultural advindo do fato de que os Pankararu se colocaram nesses espaços como uma população etnicamente diferenciada.

\footnotetext{
${ }^{9}$ Esse contato se deu com outros grupos de Pernambuco e do Nordeste, mas particularmente junto aos Guarani de São Paulo, população nativa da região, com quatro aldeias na área metropolitana de São Paulo, e que já há muito tempo mantinham práticas de associativismo com algumas associações já constituídas e atuantes junto ao poder público e sociedade civil.
} 
Se de fato, como bem demonstra a etnologia dos povos indígenas do nordeste (Grunewald, 1993; 2001, Palitot, 2005, Albuquerque, 2005, Barbosa, 2003; 2005, Valle, 1999, Mota, 2005), as emergências étnicas, com o incremento de elementos e performances culturais desses povos, ocorreram em diálogo com o estado e a sociedade envolvente, onde tais agências constituíram um importante papel na experiência étnica desses grupos, então, em São Paulo com os Pankararu, esse fenômeno repetiu-se, porém, com sua singularidade. Agora, um tipo específico de demanda (digamos pós-moderna ${ }^{10}$ ), por tradições, culturas, e autenticidades nativas, produziu um fenômeno inverso ao das emergências étnicas do nordeste, trata-se agora de pensar "a forma como o 'resgate cultural indígena' está levando o indígena para fora de sua aldeia" (Mota, 2008: 22).

Esses espaços de valorização do multiculturalismo, com todas as exigências por exotismo e autenticidade, demandadas por seu público ${ }^{11}$, carregam no seu curso também os indígenas em diáspora. Nesses espaçosos Pankararu construíram a performance "dança dos praiás" como um sinal diacrítico e como linguagem simbólica de ingresso em tais locais, assim, conseguiram atualizar sua condição étnica diferenciada e re-significar sua diáspora de forma positiva afirmando sua natureza política.

Levando em conta as agências que se encontram e se somam nesses espaços de visibilidade social indígena, defino tais locais como arenas, recuperando assim o sentido de campo de Bourdieu $(1989 ; 2004)^{12}$. Na antropologia contemporânea, o termo arenas é uma

\footnotetext{
10 "Após décadas em que a assimilação de ex-escravos e de nativos era considerada o modelo para a incorporação dessas diversas populações, ainda que dentro de um quadro hierárquico no qual continuavam constituindo as classes subalternas, um pluralismo cultural, impulsionado também por movimentos de afirmação étnico-raciais, emergiu dando lugar a um outro paradigma sociopolítico no qual as tradições e as etnias nativas eram celebradas como tais. $\mathrm{O}$ que antes era visto negativamente tornou-se um valor. Na pósmodernidade esses movimentos tendem a ser engolfados em um modelo do que poderíamos chamar de mercantilismo cultural, numa "nova era capitalista" onde bens culturais, da chamada tradição ancestral de um povo, tornam-se mercadorias, servindo aos propósitos tanto das classes dominantes como dos próprios indígenas"(Mota, 2008: 23).

11'"Esta imagem de um 'índio autêntico' tem sido divulgada principalmente por uma parcela da sociedade brasileira não-indígena, correspondendo ao desenvolvimento de um movimento alternativo conhecido como o new age. Essa visão aproxima-se muito da visão do 'bom selvagem' preconizada por [Jean-Jacques] Rousseau" (Mota, 2008: 23).

${ }^{12}$ Para Bourdieu (1989: 156-7) "Toda a história do campo social está presente, em cada momento, em forma materializada - em instituições (...) - e em forma incorporada - nas atitudes dos agentes que fazem funcionar estas instituições ou que as combatem (...) A posição social adequadamente definida é a que dá a melhor previsão das práticas e das representações; mas para evitar que se confira (...) à identidade social (...), a função de uma essência de que derivariam todos os aspectos da existência histórica - (...) - é preciso ter em atenção de modo muito claro que este status, como o habitus que nele se gera são produtos da história, susceptíveis de serem transformados, de modo mais ou menos difícil, pela história".
} 
denominação geral que se refere aos espaços de negociação e constituição de autenticidade dos conteúdos sociais. Estas arenas, que se constituem em um campo de disputa (em torno da legitimidade de seu conteúdo e regras), veem se apresentando como espaços de renovação do movimento indígena na medida em que tornam visível a presença dessa população em São Paulo, constituem lugares de congregação da comunidade, de encontros interétnicos, além de tornar acessível essa "cultura exótica" a um grande público. Essas arenas se constituem em um conjunto heterogêneo formado, por exemplo, por museus, galerias, feiras de artesanato, escolas, faculdades, instituições de pesquisa, ONG`s, exposições de cunho internacional, veículos midiáticos (TV, jornais, rádio, etc.) e outros.

A seguir demonstrarei como a "dança dos praiás" se constituiu numa versão pragmática, ou, numa tradução heterodoxa de uma modalidade ritual como um sinal diacrítico que pretende $\operatorname{cooptar}^{13}$, de forma contra-hegemônica, a imagem da diferença nas arenas de São Paulo. Essa imagem da diferença, cujo regime tem por modelo o "museu" (Price, 2000; Clifford, 1998), institui o anonimato e a atemporalidade, violência simbólica que atualiza categorias do poder tutelar (como, por exemplo, as de "aculturado", "civilizado", “desaldeado" e outras).

Clifford (1999: 192) definiu o museu como uma zona de contato, um espaço, "no qual pessoas geograficamente e historicamente separadas entram em contato umas com as outras e estabelecem relações, normalmente envolvendo condições de coerção, desigualdade radical, e intratável conflito" (tradução minha). Ao monopolizar o discurso imagético da história e se colocar como porta-voz oficial do estado, o museu invisibiliza a violência da ocupação colonial e atualiza a violência simbólica do poder tutelar ao impor à representação do indígena e de suas tradições o duplo papel de: a) anonimato; e b) de neutralidade histórica e espacial (Clifford, 1999; 1998; Price, 2000). Negando assim que os povos indígenas e suas tradições estão na história e, negando a contemporaneidade, a heterogeneidade e o caráter contra-hegemônico destas tradições.

\footnotetext{
13 1. Agregar; 2. Admitir numa sociedade, por escolha dos seus próprios membros, com dispensa das formalidades de praxe" (http://michaelis.uol.com.br/moderno/portugues/index.php?lingua=portuguesportugues\&palavra=cooptar), ou ainda; 3.Atrairajuda (http://pt.wiktionary.org/wiki/cooptar).
} 
Com o conceito de interculturalidade procuro enfatizar que esse sinal diacrítico, "dança dos praiás", deve ser pensado de um ponto de vista processualista que confira a tal tradução o poder de questionar e dialogar com noções essencialistas de autenticidade, anonimato e atemporalidade demandadas aos indígenas em tais arenas pelo modelo do "museu". A gênese dessa tradução se encontra: a) na interseção de várias agências nessas arenas onde, no jogo do poder simbólico, essa tradução intercultural cria a ilusão de consenso; e, b) nas estratégias nativas de negociação (entre o tradicional e o moderno) da autenticidade, política e ritual, de tal tradução.

\section{Traduzindo... da "dança" dos praiás nos terreiros à "dança dos praiás" nas arenas}

A performance que estou analiticamente denominando de "dança dos praiás" é chamada pelos Pankararu em São Paulo de "apresentação". Essa "apresentação" se constitui numa performance heterodoxa de uma dança ritual originalmente realizada apenas dentro da área Pankararu em Pernambuco, sempre num terreiro e por dançadores usando uma veste sagrada chamada de praiá (saiote e máscara), no contexto de um culto religioso típico de um complexo ritual comum aos povos indígenas do nordeste brasileiro. Essas apresentações em São Paulo são realizadas em determinadas arenas que veem se constituindo em espaços de visibilidade social da população indígena na cidade. Pretendo mostrar que os Pankararu em São Paulo instituíram a "dança dos praiás" como uma performance com a intenção de cooptar a imagem da diferença que os institui como indígenas (portanto, como o outro, a diferença) na sua relação com a sociedade nacional.

Desse modo, como recurso analítico, faço uma distinção entre "dança" dos praiás e "dança dos praiás". 


\section{A “dança” dos praiás nos terreiros Pankararu em Pernambuco}

Começando por uma descrição do praiá propriamente dito, ele é uma "veste" ou "roupa", constituída de algumas peças: uma máscara ou tunã cobre todo o rosto e corpo de um dançador (dançarino) feita da palha de caroá (croá, kroá, caroá-açu); um saiote, feito do mesmo material; uma coroa, rodela de plumas, feita de penas de peru; um penacho feito de plumas que se encaixa num pequeno orifício no centro, em cima da máscara ou tunã; e uma cinta, um tecido colorido, normalmente tecido de chita estampado ou algum pano bordado com um símbolo religioso. Ela é usada por um dançador (dançarino) portando na mão direita um instrumento musical, o maracá (espécie de “chocalho"), e geralmente presa a máscara uma gaita (flauta doce). O dançador utiliza o praiá durante uma festa cerimonial, principalmente, em homenagem a um feito milagroso, uma cura em geral, atribuído à ação de uma entidade sagrada, genericamente chamada de encantado, cuja representação material é o próprio praiá. 


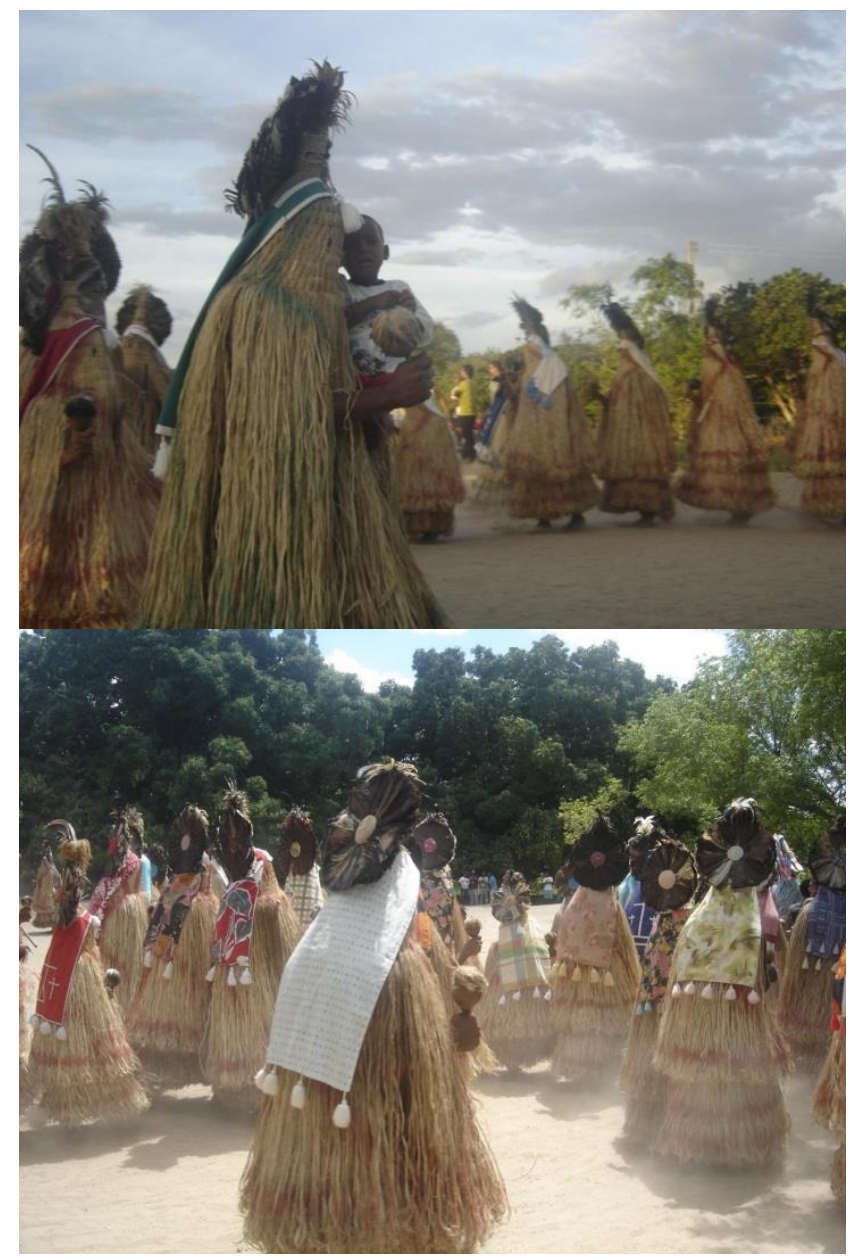

Fotos: Maria dos Dores Conceição Pereira do Prado.

Os encantados são entidades sagradas que habitam na natureza, são atributos de Deus, elas são entidades vivas, já que são seres que não morreram, sendo entendidos como ancestrais dos Pankararu que se encantaram, ou seja, passaram para o plano espiritual, porém sem passarem pela experiência da morte, por isso continuam vivos no plano terrestre, mas habitando não mais entre os homens, mas na natureza, nas matas e principalmente nas quedas d água ${ }^{14}$. São, portanto seres especiais que estão tanto na "terra"

${ }^{14}$ Como escreveu Arruti (1999: 269), “Os Encantados são 'índios que se encantaram', voluntária ou involuntariamente, e por isso o culto a eles, como insistem os Pankararu, não pode ser confundido com o culto aos mortos, identificado como a 'religião de negros"'. A atuação do encantado no médium é uma relação de irradiação e não de incorporação. Essa distinção pretende construir, no discurso da etnicidade, uma diferença com relação aos cultos afro-brasileiros, cujo médium incorpora o espírito de uma entidade "morta" (como o preto-velho, a pomba-gira, o boiadeiro, etc.). No caso dos Pankararu o médium apenas irradia, ou seja, realiza um contato cuja incorporação difere essencialmente pelo fato de que o encantado não é o espírito de 
quanto no "céu", como seres que estão em "ambiguidade" eles estão tão próximos de Deus quanto dos homens, e portanto a eles se pode recorrer em auxilio para orientação e proteção espiritual, pessoal, familiar, da comunidade e, principalmente, para a realização de uma cura, a recuperação da saúde de uma pessoa, entendida como um milagre.

Analiticamente os encantados fazem parte de um complexo religioso cuja distinção e definição foi proposta por Mota \& Barros (2002) e Nascimento (s/d.) como sendo o "complexo da jurema". Campo religioso afro-indígena cuja linguagem ritual guarda a herança colonialista católica e as alianças territoriais, simbólicas e de parentesco entre os povos autóctones e escravos negros durante a formação histórica da região nordeste do Brasil. Particularmente entre os Pankararu, os encantados são o centro de um complexo terapêutico ${ }^{15}$ onde são considerados um atributo de Deus que atuam no plano humano a partir da instituição da "promessa" (relação de dádiva e contra-dádiva que uma pessoa contrai com essas entidades) para a realização de um milagre (intervenção dos encantados na recuperação da saúde e cura de uma pessoa).

A emergência, ou em termos nativos, o levantamento de um praiá começa com o aparecimento da semente que "é a forma material por que os Encantados se manifestam pela primeira vez aos Pankararu" (Arruti, 1999: 269). Os encantados escolhem uma pessoa para zelar por eles, aparecem em sonho, as informam de suas intenções e lhe entregam a semente. Ela é então guardada em um pote e enterrada no solo embaixo da casa do zelador (a pessoa que fica então responsável pela guarda e preservação das máscaras corporais dos praiás). Deste modo, os encantados passam a se manifestar no particular (culto doméstico, às vezes chamado de mesa, restrito a poucas pessoas, normalmente os familiares mais próximos), neste espaço eles revelam seu nome e seu toante (cântico) próprio. Isso significa que cada encantado tem um nome próprio e um toante próprio (do mesmo modo que terá em seguida uma veste, ou um praiá, próprio que o identifica através da cinta).

uma pessoa morta, mas sim o espírito de um ser encantado, algo vivo, na natureza e no plano humano, na Terra.

${ }^{15}$ Estou utilizando a palavra terapia recuperando o seu sentido original, já que terapia vem do grego $\theta \varepsilon \rho \alpha \pi \varepsilon i ́ \alpha$, que significa literalmente "servir a deus". 
Depois disso o encantado pede para ser levantado, ou seja, cultuado nos terreiros, nesse momento possivelmente o encantado já mostrou sua força realizando algum tipo de cura, assim ele está apto a pisar no terreiro (um espaço público diferente do particular) e ser conhecido pelo resto da comunidade. Neste momento então é que o zelador constrói, ou seja, organiza uma equipe de especialistas, somente homens, que tecerão a indumentária característica dos praiás, máscara e saiote. Às mulheres cabem tecer a cinta, um tecido retangular com nome do praiá ou símbolos religiosos bordados ou ainda pode ser usado um pano de chita estampado ou liso. Este zelador convoca então em sigilo (tendo em vista que às mulheres é vedado conhecer a identidade daquele que está usando o praiá) um homem jovem da comunidade para "vestir" o praiá. Para esta função o jovem deve ser alguém de conduta moral reconhecível. Do mesmo modo, também "não é qualquer pessoa que é reconhecida como apta a receber uma 'semente', estando esse lugar marcado por certa avaliação coletiva acerca de sua reputação" Arruti (1999: 271). O zelador passa a concentrar em torno de si a realização de particulares e deve manter um terreiro para a realização das cerimônias públicas (Menino do Rancho, Três Rodas e outras).

Para manter vivos os praiás alguns ritos devem ser realizados e alguns tabus devem ser seguidos. Os mais importantes atos rituais nesse sentido são: a) alimentá-los todo dia, ou seja, através do campiô (cachimbo ritual) defumá-los com fumo preparado; b) isso deve ser realizado por um homem, normalmente seu zelador, esse não pode ter tido relações sexuais no dia ou na véspera e não pode ter ingerido bebida alcoólica, também não deve ser feito na presença de muitas pessoas, principalmente não indígenas; e, c) os dançadores devem seguir os mesmos tabus e ritos acima descritos, praticados pelo zelador, na véspera e no dia de vestirem o praiá.

Segundo Carneiro da Cunha (1999: 56-7) é possível classificar o número de praiás em três gerações: a) inicialmente eram oito, depois somaram-se mais cinco totalizando treze praiás iniciais; b) mesmo com a presença de faccionalismos ao longo dos anos 1970 e 1980 entre a TI Pankararu e a TI Entre-Serras, o número de praiás cresceu em apenas algumas unidades; e, c) Carneiro da Cunha (1999: 57) registrou em sua pesquisa que o número de praiás ultrapassava os cinquenta. Durante o ano de 2009, eu registrei uma cerimônia do Menino do Rancho na aldeia sede dos Pankararu, no seu terreiro principal 
(Fonte Grande), onde se pôde contar mais de sessenta praiás. O número de praiás atualmente não é conhecido, mais alguns dizem que ultrapassa facilmente os cem.

Como registraram vários autores (Carneiro da Cunha, 1999; Arruti, 1999; Matta, 2005), novos praiás são mal vistos, ou pelo menos, colocados em suspeita, por muitos Pankararu que têm uma postura mais ortodoxa com relação à ampliação do número de praiás, normalmente esse grupo mais crítico é formado por pessoas mais idosas. Além do seu aspecto ritualístico, levantar um praiá significa se colocar de forma mais ampla nos espaços coletivos de celebração, já que os praiás são identificados com as famílias que os possuem. A organização social dos Pankararu distribui o poder político no seio das famílias influentes no campo das qualificações rituais, onde tanto o número quanto a antiguidade dos praiás são importantes ${ }^{16}$.

Com relação especificamente aos Pankararu, o toré é o nome usado pra se referir tanto a um ritual, quanto ao tipo de dança e de música nele executados ${ }^{17}$. Os torés, enquanto músicas, são cânticos religiosos, que na sua maioria fazem referencia ao universo do que denominei acima de "o complexo da jurema", onde se destacam Jesus, Deus, os encantados, santos católicos, e outros. Esses tipos de cânticos são entoados na sua maior parte em português, por um especialista na execução de cânticos cerimoniais, chamado de cantador, e sempre como encerramento de um ritual, ocasião que também é chamada de toré ou de "brincadeira", momento mais lúdico, onde há a participação coletiva.

Já os praiás, como já foi dito, são máscaras corporais que "vestem" os encantados durante um ritual (que pode durar mais de um dia) sempre num terreiro (lugar sagrado reservado para essas ocasiões). No caso dos praiás, embora eles compartilhem do momento do toré, os rituais propriamente ditos, são realizados “para que os praiás dancem”, é uma festa dada a eles, desse modo, o toré é uma espécie de momento lúdico que acompanha o fechamento (encerramento) de um ritual feito para os encantados dançarem com os praiás no terreiro. Durante a "dança" dos praias um cantador executa cânticos cerimoniais

\footnotetext{
${ }^{16}$ Outra forma de adquirir praiás é por herança, com a transmissão de um praiá ou mesmo um batalhão pela linha de parentesco.

${ }^{17} \mathrm{O}$ toré é uma importante manifestação política e cultural dos povos indígenas no nordeste e se tornou uma importante referência para todas essas populações. Na medida em que o toré se constituiu em diferentes contextos, em diferentes comunidades indígenas ele vai adquirindo certas características próprias, existindo portanto uma enorme gama de manifestações entre os povos indígenas que são chamadas de toré (ver, por exemplo, Grunewald, 2005).
} 
diferentes dos que são executados durante o toré. $\mathrm{Na}$ "dança" dos praiás são executados cânticos chamados de toantes. Os toantes são cânticos feitos numa espécie de língua ancestral Pankararu, eles são compostos tantos de palavras vindas de uma linguagem ancestral, como também por sons que representam essa linguagem e ainda por vocábulos em português normalmente pronunciados de maneira a se adequar ao som da música em conformidade a essa linguagem ancestral.

Simplificando sobremaneira se pode dizer que o toré, referindo-se ao seu conjunto e nas suas partes (ritual, canto e dança), apesar de sagrado é público e tem características laicas, congregando muito bem elementos puramente religiosos com manifestação e performance estética e política, sendo executado em momentos rituais como "brincadeira" dentro das aldeias e em momentos políticos como performance. O praiá (máscara corporal, dança e toante) é restrito a rituais religiosos específicos (Menino do Rancho, Três Rodas, Dança dos Passos, e outros) que ocorrem apenas em terreiros que se localizam sempre dentro das TI`s dos Pankararu, portanto, por regra, sua ortodoxia não permite seu ingresso em espaços que não sejam terreiros em aldeias ${ }^{18}$. O toré é então realizado tanto internamente como "brincadeira" na comemoração de festas, na parte final dos rituais mais importantes, e outros, quanto fora da área Pankararu, como exibição de identidade e força política, já a "dança" dos praiás, pelo seu caráter mais sagrado, ficam restritas aos terreiros das aldeias. (Sandroni et. al., 2005; Arruti,1999; e Carneiro da Cunha, 1999).

\footnotetext{
${ }^{18}$ Além do caso em são Paulo, vale a nota de que entre os Pankararu existe a devoção a padre Cícero, e durante as comemorações da festa de padre Cícero, os Pankararu realizam romarias até a cidade de Juazeiro, do mesmo modo que muitos sertanejos pelo nordeste, mas o diferencial dos Pankararu, além de outros obviamente, é que alguns Pankararu chegam a levar praiás para a cidade e a festa santa. Além desse momento é importante notar também que os praiás Pankararu podem eventualmente "dançar" em outros terreiros dentro de outras áreas indígenas, particularmente daqueles reconhecidas como "parentes" próximos dos Pankararu. Do mesmo modo que praias desses locais podem "dançar" em festas na área Pankararu.
} 


\section{A “dança dos praiás” nas arenas de São Paulo}

Em São Paulo, não existe nenhum terreiro Pankararu, isso significa que em teoria não deveriam existir praias na cidade, visto que os praiás nesse contexto não teriam função ritual propriamente dita, na medida em que apenas num terreiro eles poderiam "dançar". Portanto, a emergência de praiás entre os Pankararu do Real Parque é uma heterodoxia, já que ela somente pôde ocorrer ao relativizar a ortodoxia ritualística que rege o ato de levantar o praiá, como exposto acima. De maneira analítica, pode-se dizer que o ato de levantar praiás em São Paulo modificou-se, passou de um discurso ritual para um político. Portanto, é pelo e como um ato político, atualização dupla no jogo do poder, que rigores rituais atualizam-se como condição de responder à violência simbólica, atualização de categorias do poder tutelar, das arenas de São Paulo.

Em entrevista, o ex-presidente da SOS-CIP, Manuel Alexandre Sobrinho, o Bino, disse que,

\footnotetext{
"logo que cheguei aqui [São Paulo] nosso povo não se identificava como índio, eles tinham vergonha de mostrar a cultura, tinham cisma também das empresas não aceitar se você é índio. Aqui não tinha praiá, não tinha toré, nós não nos reuníamos pra fazer nosso trabalho de mesa. Nós começamos a dançar o toré, os praiá, e se identificar, depois da associação. Lutamos por ela porque a FUNAI não queria nos atender como índio, porque eles acham que índio só é índio na aldeia, como a FUNAI queria tirar o corpo dela fora pra não assumir nós com nada, ela botou essa dificuldade, só nos apoio depois que viu a nossa cultura".
}

Foi nesse contexto que os Pankararu tomaram a decisão de consultar o cacique, o pajé, e as demais lideranças de Pernambuco "pra nós trazermos os praiá aqui pra São Paulo".

No ano de 2008 a SOS-CIP realizava apresentações da performance "dança dos praiás" com um grupo de dez praiás. Esses praiás não foram levantados de forma usual, ou seja, como um ato ritual após o aparecimento da semente, eles foram levantados como um ato político. Os praiás em São Paulo são considerados a segunda roupa, já que a primeira, também chamada de o tronco velho, a originalmente levantada pelo circuito ritual da 
semente, está na aldeia em Pernambuco. Sendo assim, todos os dez praiás em São Paulo são cópias de praiás de sua aldeia em Pernambuco, são a segunda roupa de outros praiás ${ }^{19}$.

Em São Paulo o primeiro praiá segunda roupa foi levantado oficialmente pela diretoria da SOS-CIP através de seu primeiro presidente, Frederico Marciolino de Barros, em 1994. Nesse ano Frederico trouxe da aldeia sede dos Pankararu, Brejo dos Padres, um praiá chamado "Cinta Vermelha", que é a segunda roupa deum dos primeiros praiás a ser levantado entre os Pankararu ${ }^{20}$. Em fins de 1999, Bino, que fazia parte da diretoria da SOSCIP, trouxe a fibra de caroá da aldeia e, tendo a presença de um artesão Pankararu que estava no Real Parque, foram levantados mais três praias segunda roupa, totalizando quatro. Nessa época, Bino havia retornado da aldeia em Pernambuco com dois praiás pequenos, usados por crianças, também considerados como a segunda roupa, totalizando assim seis praiás. Todos esses praiás segunda roupa, pertencem ao batalhão original do "Cinta Vermelha" no Brejo dos Padres.

Dimas Nascimento, após derrota na tentativa de reeleição como presidente da SOSCIP em 2003, constituiu uma ONG, a Ação Cultural Indígena Pankararu. A dinâmica dessa ONG procurava parceiros na iniciativa privada para a confecção de "projetos culturais" com o objetivo de "'resgatar e conservar" aspectos da cultura dos Pankararu. Essa ONG constituiu, tal como a SOS-CIP, uma performance da "dança dos praiás". Para tanto, Dimas levantou, no Brejo dos Padres, quatro praias segunda roupa e os trouxe para São Paulo. Tal procedimento acirrou o faccionalismo entre a SOS-CIP e essa ONG, colocando em jogo a própria legitimidade dos Pankararu como comunidade indígena em São Paulo.

\footnotetext{
${ }^{19}$ Um praiá segunda roupa é tão legítimo quanto o original. O fenômeno da segunda roupa não é um ato isolado dos Pankararu em São Paulo, de fato ele ocorre também nas suas aldeias em Pernambuco, mas esse fenômeno ainda não foi bem descrito pela literatura antropológica.

${ }^{20}$ O primeiro praiá levantado foi o do "Mestre Guia", que se constitui no principal encantado e cujo praiá "dança" no terreiro apenas uma vez ao ano, no encerramento da festa "corrida do Imbu". Para muitas pessoas, o "Cinta Vermelha" e o "Xupunhum" são os primeiros praiás depois do "Mestre Guia". O "Cinta Vermelha" é o chefe de um batalhão importante no Brejo dos Padres, isso significa que esse encanto é o cabeça, o guia de todo um conjunto de praiás, é o chefe que vai na frente durante a "dança" dos praiás, e também é o chefe que normalmente comanda a realização de um milagre, sendo uma espécie de coordenador do processo terapêutico.
} 
Do ponto de vista desse caso específico, o associativismo indígena Pankararu em São Paulo é o resultado de outra atualização do poder tutelar, já que restitui a indianidade ${ }^{21}$ (Oliveira, 1988) como condição de representação política. Aqui, ele gerou o monopólio da representação política dessa comunidade em todo o Estado, e isso porque os Pankararu em São Paulo passaram a ser assistidos pela FUNAI em Bauru (SP), sendo a SOS-CIP, a entidade formal e representante oficial dessa comunidade junto ao poder público. O associativismo, única saída possível aos Pankararu para garantirem algum tipo de atendimento pelo órgão tutor (saída improvisada, diga-se de passagem, tendo em vista continuarem num "limbo jurídico") acabou constituindo um novo tipo de indianidade, cuja forma definiu como instrumento de representação a suposta coerência e homogeneidade da comunidade em São Paulo.

O modelo de organização social Pankararu em Pernambuco é baseado em núcleos familiares que são donos de batalhões e terreiros, desse modo, o poder político é atrelado ao religioso, permitindo assim apenas uma relativa autonomia do cacique e do pajé. Em São Paulo ocorreu um espelhamento e uma síntese desse modelo, no caso, a SOS-CIP e sua presidência, por ter o monopólio político, passou a reivindicar também o simbólico, ou seja, o de representar oficialmente os Pankararu através da performance "dança dos praiás" em arenas da cidade de São Paulo.

Desse modo, em 2003, as duas entidades Pankararu em São Paulo, a SOS-CIP e a ONG, realizavam apresentações com a performance "dança dos praiás”. Essa performance se constituía numa síntese da "dança" dos praiás original reduzindo o que normalmente demora o dia inteiro (ás vezes até mais de um) em apenas algumas horas, ou, muito mais comum, em cerca de 40 minutos. Nessa época, portanto, a diretoria da SOS-CIP não estava contente com o fato da ONGestar realizando apresentações públicas com praiás, já que tal elemento cultural, sendo "o mais significativo dos Pankararu” não poderia ser usado por uma entidade que não fosse também a legitima representante da comunidade em São Paulo.

\footnotetext{
21 "Em função do reconhecimento de sua condição de índios por parte do organismo competente, um grupo indígena específico recebe do Estado proteção oficial. A forma típica dessa atuação/presença acarreta o surgimento de determinadas relações econômicas e políticas, que se repetem junto a muitos grupos assistidos igualmente pela FUNAI, apesar de diferenças de conteúdo variadas das diferentes tradições culturais envolvidas. Desse conjunto de regularidades decorre um modo de ser característico de grupos indígenas assistidos pelo órgão tutor, modo de ser que eu poderia chamar aqui de indianidade para distinguir do modo de vida resultante do arbítrio cultural de cada um" (Oliveira, 1988: 14. Em itálico no original).
} 
Além disso, essa disputa colocava em cheque a legitimidade dos Pankararu em São Paulo, da própria SOS-CIP e da presença dos praiás em apresentações, já que o ingresso dos praiás nesse sistema de apresentações e, portanto, na constituição de outro status dos praiás através do discurso do levantar como um ato político, foi largamente negociado com as lideranças Pankararu em PE que, após várias intermediações, inclusive com a presença dessas lideranças em São Paulo em reuniões com a SOS-CIP, concederam que alguns poucos praiás pudessem fazer parte da SOS-CIP constituindo, assim, um pequeno batalhão para servir de referência cultural e religiosa aos Pankararu em São Paulo, e incrementar o trabalho de valorização da identidade indígena dos Pankararu perante os órgãos públicos e a sociedade paulistana em geral. Para dar conta do entrave político que se gerou entre as lideranças em São Paulo, e como forma de evitar um desgaste dessas lideranças e com isso do poder político da própria comunidade, o representante da pastoral indigenista, Benedito Prézia, que atuava junto aos membros da ONG desde a época em que eram a "situação" na SOS-CIP, interveio junto a Dimas, presidente da ONG, e conseguiu uma conciliação com a passagem dos quatro praiás para a SOS-CIP.

Desse modo, em 2008, Bino, presidente da SOS-CIP, era o zelador de um batalhão de dez praiás segunda roupa. Com esse conjunto ele e os membros da SOS-CIP já haviam realizado apresentações da performance "dança dos praiás" em diversas arenas da cidade de São Paulo: escolas públicas, igrejas, faculdades particulares, ONG`s, parques de exposição, feiras de artesanato, formatura de alunos Pankararu, festas do "dia do índio", na Casa de Saúde Indígena (CASAI-SP),eventos culturais (principalmente a Virada Cultural), apresentação na Assembleia Legislativa (SP), sarais poéticos (como o evento "I Sarau Indígena" na Av. Paulista), encontro da entidade de moradores do Real Parque (SARP), no protesto "Marcha Grito dos Excluídos" evento que congrega milhares de pessoas e é promovido por diversas entidades sociais, encontros de lideranças indígenas, e muitos outros. 


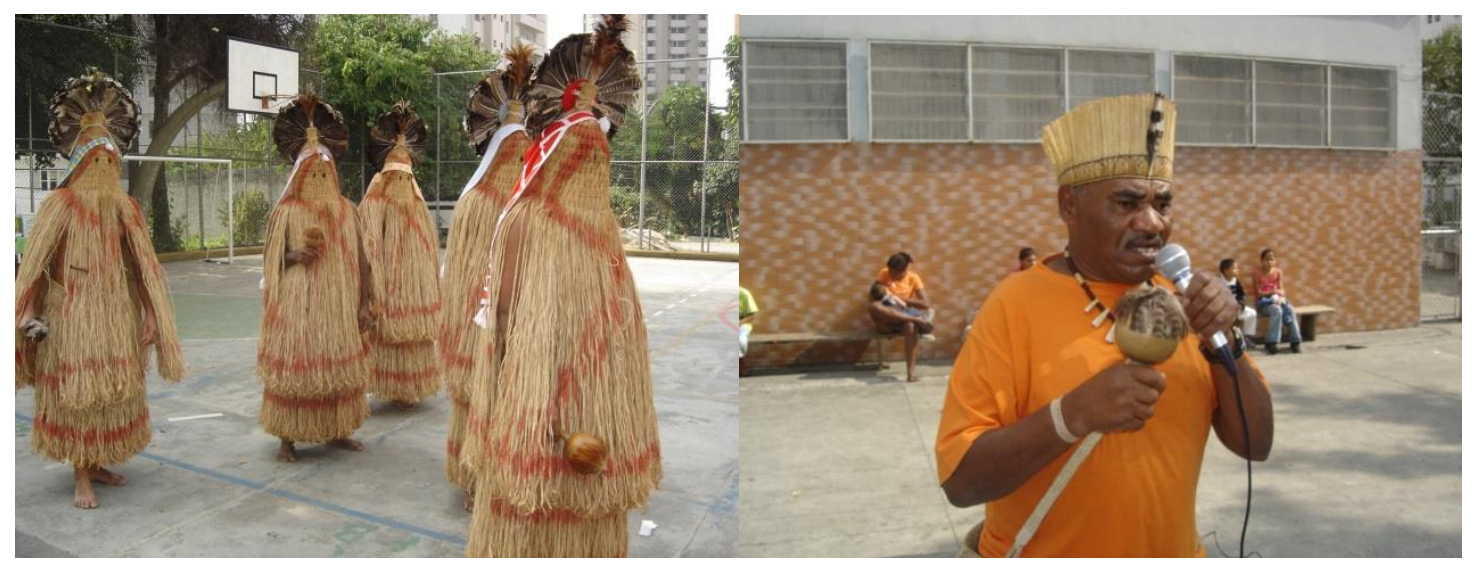

Fotos: na esquerda o batalhão de praiás de São Paulo em uma "apresentação", na direita Bino comanda a performance. Autor das fotos: Marcos Alexandre dos Santos Albuquerque.

A segunda roupa é um duplo, ela representa literalmente o encantado tal como o praiá original, por isso, com relação a segunda roupa, todos os ritos e tabus relacionados ao praiá original devem ser seguidos. Desse modo, em São Paulo, “continuam latentes as potencialidades e os perigos inerentes ao uso da vestimenta dos praiás e à prática ritual, independente da dose política investida na produção dos encantados e na 'apresentação' do rito" (Matta, 2005: 181). A legitimidade dos praiás que estão em São Paulo e sua força são "atestadas ao passo que os pedidos a eles proferidos forem concretizados" (ibid.: $178)^{22}$.Assim, o ato político de levantar os praias em São Paulo embora uma heterodoxia, não o destituiu da ortodoxia que o mantém vivo. Esse ato apenas pode ser atualizado a cada apresentação se o ato ritual que mantém os praiás vivos for cotidianamente atualizado também.

Zelar (cuidar), alimentar (com fumo) e vestir (usar pelo dançador), todos os atos rituais descritos acima sobre a forma como se mantém vivos os praiás em Pernambuco, devem ser seguidos à risca em São Paulo, sob pena de quem infligi-lós "ser corrigido" pelo encantado (como por exemplo, sentir um mal estar com cegueira e incapacidade de se movimentar momentâneas). Foi como e por um ato político que a segunda roupa pôde

\footnotetext{
${ }^{22}$ Isso significa que o complexo ritual que contém os praiás continua existindo entre os Pankararu em São Paulo. No Real Parque existem alguns curadores ou rezadores Pankararu que realizam alguns cultos e rituais, tal como fazem em Pernambuco, como a benzedura e os chamados trabalhos de mesa. Também são realizados os "pagamentos de promessa" mais simples: a garapa e o prato. Os rituais de "pagamento de promessa" mais complexos e dispendiosos necessitam da existência de um terreiro, é o caso das Três Rodas e do Menino do Rancho, e são realizados apenas em Pernambuco.
} 
nascer em São Paulo, mas é apenas pelo ato ritual que ela pode sobreviver. A segunda roupa tem status ritual igual ao da original porque sua gênese como um ato político atualiza o ato ritual que deu origem ao praiá original.

\section{"A árvore tem folhas": acultura política do ato de traduzir}

Durante a formação do seu território atual os Pankararu passaram por muitas mudanças sociais, culturais, fenotípicas, linguísticas que são a prova e o resultado mais contundente da ação do poder tutelar como dispositivo político-administrativo. Dentre um número muito grande de mudanças há algumas que são mais tipicamente levantadas contra os Pankararu em geral e, mais particularmente, contra os que estão em São Paulo. Como já foi dito, o discurso das arenas em São Paulo ao atualizar categorias do poder tutelar, pretende instituir um modelo (o "museu") de autenticidade, e, no caso específico dos Pankararu, tal modelo opera com três categorias paradigmáticas: "assimilados", “aculturados", e “desaldeados", em três níveis:

a) "Assimilados": ao serem questionados por não possuírem uma "cara de índio", os Pankararu atuais são, de forma inversa, acusados pela violência da qual foram vítimas, já que eles não possuem um fenótipo característico das populações nativas devido ao fato de serem uma população formada pela concentração de diversos povos nativos em uma mesma área e, paralelamente, incorporaram escravos fugidos;

b) "Aculturados": a ausência de uma língua ancestral demonstraria que essa população já não possui traços aborígenes, portanto teriam sido completamente "aculturados". Apelo extemporâneo que pretende negar outra lógica de apropriação de uma linguagem geral. O português obviamente se tornou uma língua geral no seio da população genericamente chamada de Pankararu devido a dois fatores, primeiro o fato dessa população ser fruto da união de vários povos diferentes, nativos e de ex-escravos, e, segundo, por estarem durante esse processo sob a gestão de uma ordem religiosa católica e, depois, do poder tutelar, que desencorajava o uso de idiomas nativos e promovia o português como língua geral; 
E, c) "Desaldeados": supostamente auto exilados nas cidades, pareciam então ter abdicado voluntariamente da "proteção" do poder tutelar e, mais contemporaneamente, da assistência dos órgãos públicos (FUNAI, FUNASA, e outros). Mecanismo de invisibilização da violência do processo colonial e do poder tutelar, tal categoria pretende contestar a miséria e a violência no campo que produz as diásporas como estratégia de continuidade social e de sobrevivência cultural.

Como o poder tutelar é também uma empresa cognitiva, orientada por procedimentos semióticos (Souza Lima, 1995), esse mecanismo do "jogo do poder" é sentido e expresso pelos Pankararu pela noção nativa de "preconceito". O "preconceito" cria a invisibilidade social do indígena e coloca em risco os direitos garantidos a essa parcela da população pela própria constituição. Essa violência simbólica é combatida pelos Pankararu através da performance "dança dos praiás", uma tradução intercultural contra hegemônica, cujo ato político de gênese permite caracterizá-la como constituindo uma versão heterodoxa da dança ritual dos praiás. E, cuja intenção do ato político dessa e nessa tradução é dotar os Pankararu de capital simbólico nas arenas da cidade de São Paulo. Tais arenas podem ser definidas como sendo um campo (Bourdieu, 1989) de visibilidade social onde a violência simbólica do modelo "museu" de representação dos indígenas, atualiza, pelo menos, três grandes categorias do poder tutelar ("assimilados", "aculturados", e "desaldeados") ao demandar aos Pankararu a ambígua tarefa social de restituírem-se, sob a continuidade da violência colonial, os estigmas fenotípicos ("cara de índio"), linguísticos ("idioma ancestral"), e político-administrativos (isolamento e distância temporal e espacial).

Teoricamente interpreto essa noção de "preconceito" como sendo a ação do poder simbólico, um "poder subordinado", uma "forma transformada, quer dizer, irreconhecível, transfigurada e legitimada, das outras formas de poder", onde, "o trabalho de dissimulação e de transfiguração (numa palavra, de eufemização) que garante uma verdadeira transubstanciação das relações de força fazendo ignorar-reconhecer a violência que elas encerram objetivamente e transformando-as assim em poder simbólico, capaz de produzir efeitos reais sem dispêndio de energia" (Bourdieu, 1989: 15) ${ }^{23}$.

${ }^{23}$ Como definiu Bourdieu (1989: 09), “os 'sistemas simbólicos', como instrumentos de conhecimento e de
comunicação, só podem exercer um poder estruturante porque são estruturados", desse modo, "os símbolos 182 
Pela sua natureza, o "preconceito" tem origens indeterminadas, já que "o poder simbólico é, com efeito, esse poder invisível o qual só pode ser exercido com a cumplicidade daqueles que não querem saber que lhe estão sujeitos ou mesmo que o exercem" (ibid.: 07-8). O "preconceito" é a atualização da "guerra de conquista" dos povos indígenas via a "política como guerra", violência simbólica distribuída pelo corpo do poder público e da sociedade civil, já que,

"é enquanto instrumentos estruturados e estruturantes de comunicação e de conhecimento que os 'sistemas simbólicos' cumprem a sua função política de instrumentos de imposição ou de legitimação da dominação, que contribuem para assegurar a dominação de uma classe sobre a outra (violência simbólica) dando o reforço da sua própria força às relações de força que as fundamentam" (ibid.: 11).

Esse tipo de "preconceito" pode ser caracterizado como essencialmente um preconceito da autenticidade, cujo efeito, propriamente ideológico, "consiste precisamente na imposição de sistemas de classificação políticos sob a aparência legítima de taxonomias filosóficas, religiosas, jurídicas, etc.” (ibid.: 14). Se de fato o poder simbólico exerce,

\begin{abstract}
"O poder de constituir o dado pela enunciação, de fazer ver e fazer crer, de confirmar ou de transformar a visão do mundo e, deste modo, a ação sobre o mundo, portanto o mundo; poder quase mágico que permite obter o equivalente daquilo que é obtido pela força (física ou econômica), graças ao efeito específico de mobilização, só se exerce se for reconhecido, quer dizer, ignorado como arbitrário" (ibid.).
\end{abstract}

Então, a performance "dança dos praiás" constituiu-se num espaço contra hegemônico já que permitiu o ingresso e a visibilidade dos Pankararu enquanto uma comunidade etnicamente diferenciada nas arenas de São Paulo, restituindo a esses indígenas os sinais diacríticos esperados pela audiência dessas arenas.

Nesse sentido, essa performance realizou tal tarefa ambígua ao cooptar e atualizar, a sua maneira, categorias do poder tutelar, no sentido de que essa performance contém: a) a "cara de índio" através da máscara, pois ao cobrir o rosto indígena a máscara cria um outro

são os instrumentos por excelência da "integração social" já que por meio deles se torna possível o "consensus acerca do mundo social que contribui fundamentalmente para a reprodução da ordem social: a integração 'lógica' é a condição da integração 'moral”” (ibid.: 10). 
rosto, uma outra visibilidade, permitindo que o indígena possa ser identificado como "índio genérico"; b) um idioma indígena pelo uso do toante. Na "dança dos praiás" são usados os toantes tal como na "dança" dos praiás em PE. Esses toantes (cânticos realizados com fragmentos e palavras de uma língua ancestral Pankararu, e com a mistura de palavras em português e sons que simulam essa linguagem) se constituem em uma linguagem ritual, em um "idioma musical”, um veículo de comunicação étnica diferente da linguagem falada. Portanto, os Pankararu não perderam propriamente seu idioma étnico, mas sim o mantiveram vivo por outra forma; e, c) produz o deslocamento tempo/lugar, já que a apresentação da dança dos praiás produz a sensação de deslocamento, de distância temporal/passado e espacial - aldeia/rural.

Os Pankararu assim parecem ter compreendido como "luta social" o processo definido por Bourdieu (ibid.: 15) como a tomada de consciência do arbitrário,

\begin{abstract}
"a destruição deste poder de imposição simbólico radicado no desconhecimento supõe a tomada de consciência do arbitrário, quer dizer, a revelação da verdade objetiva e o aniquilamento da crença: é na medida em que o discurso heterodoxo destrói as falsas evidências da ortodoxia, restauração fictícia da doxa, e lhe neutraliza o poder de desmobilização, que ele encerra um poder simbólico de mobilização e de subversão, poder de tornar atual o poder potencial das classes dominadas".
\end{abstract}

A “dança dos praiás" se constituiu assim no instrumento simbólico de ingresso dos Pankararu de São Paulo no campo do poder simbólico, na luta por legitimidade da comunidade como indígenas, já que a intenção ao traduzir a "dança" dos praiás na performance "dança dos praiás” foi a de evocar e construir no imaginário do público dessas arenas a "cara de índio", o "idioma ancestral", e o deslocamento histórico e geográfico que os constrangia à invisibilidade.

Seguindo a ideia defendida por Oliveira (1999b: 08) de que "uma compreensão das sociedades e culturas indígenas não pode passar sem uma reflexão e recuperação críticas de sua dimensão histórica", assim, qualquer transformação nos elementos culturais de uma comunidade indígena deve ser entendido como um movimento duplo, de diálogo desta comunidade, de abertura e também de agência do grupo frente a projetos políticos e culturais amplos. Sobre a SOS-CIP, Bino costumava repetir, "se nós não tivéssemos a cultura que nós temos hoje, dificilmente a associação ia pra frente. Que índio é esse que não 
tem cultura? Eu sempre eu falo, o índio sem cultura eu considero ele uma árvore sem folha, porque o índio não tem que ter vergonha de mostrar aquilo que ele sabe, o dom que Deus deu pra ele". Política da cultura e cultura política, como escreveu Foucault,

O grande jogo da história será de quem se apoderar das regras, de quem tomar o lugar daqueles que as utilizam, de quem se disfarçar para pervertê-las, utilizá-la ao inverso e voltá-las contra aqueles que as tinham imposto; de quem, se introduzindo no aparelho complexo, o fizer funcionar de tal modo que os dominantes encontrar-se-ão dominados por suas próprias regras (2000: 25-6).

Como ato político e ritual os praiás segunda roupa foram dotados de legitimidade cuja semente segue a diáspora Pankararu, como escreveu Arruti (1999: 230), "no lugar de um etnômio, encontrei uma "árvore” (...); no lugar de uma situação e de uma narrativa, uma rede e suas conexões, que estendiam os fios da sociogénesePankararu a diversos outros grupos de "remanescentes indígenas" ao longo do São Francisco", e muito mais além... Hoje, com certeza, passando nas margens de um outro rio, o Pinheiros, onde na favela do Real Parque os mesmos Pankararu continuam "germinando" com arte as sementes queos dotam de "frondosas árvores".

\section{Referências}

ALBUQUERQUE, M. A. S. (2005). O Toré Coco (a construção do repertório musical tradicional dos índios Kapinawá da Mina Grande - PE). Campina Grande: dissertação de Mestrado, Programa de Pós-Graduação em Sociologia, PPGS/UFCG.

APPADURAI, A. (1994). Disjunção e Diferença na Economia Cultural Global. In: Cultura Global: Nacionalismo, Globalização e Modernidade. Featherstone, M (Ed.). Petrópolis, Vozes.

ARRUTI, José Maurício P. A. (1999). A árvore Pankararu: fluxos e metáforas da emergência étnica no sertão do São Francisco. In: A Viagem de Volta. Etnicidade, Política e Reelaboração Cultural no Nordeste Indígena. Rio de Janeiro, Contra Capa.

BARBOSA, Wallace de Deus. (2003). Pedra do Encanto: dilemas culturais e disputas políticas entre os Kambiwá e os Pipipã. Rio de Janeiro: Contra Capa Livraria / LACED.

, Wallace de Deus. (2005) O Toré (e o praiá) entre os Kambiwá e os Pipipã:

performances, improvisações e disputas culturais. In: Toré: Regime Encantado dos Índios do Nordeste. Org. Rodrigo de Azeredo Grünewald, Ed. Massangana (FUNDAJ). Recife. (no prelo).

BENJAMIN, Walter. (2008). A Tarefa do Tradutor In: A tarefa do tradutor, de Walter Benjamin: quatro traduções para o português. Tradução de Fernando Camacho. Belo Horizonte, Fale/UFMG. BHABHA, Homi K. (1998). O Local da cultura. Trad. de Miriam Ávila, Eliana Lourenço de Lima Reis e Gláucia Renate Gonçalves. Belo Horizonte: Ed. UFMG.

BOURDIEU, Pierre. (1989). O Poder Simbólico. Lisboa, Difel. 
, Pierre. (2004) Campo de poder, campo intelectual e habitus de classe. In: A economia das trocas simbólicas. São Paulo: Perspectiva. p. 183-202.

CARNEIRO DA CUNHA, Maximiliano. (1999). A Música Encantada Pankararu (toantes, toré, ritos e festas na cultura dos índios Pankararu). Dissertação de Mestrado. Programa de PósGraduação em Antropologia Cultural da UFPE. Recife - PE.

CLIFFORD, James. (1998). A experiência etnográfica: Antropologia e Literatura no séc. XX. Org. José Reginaldo Santos Gonçalves. Rio de Janeiro: Ed. UFRJ.

James. (1999). Museums as Contact Zones. In: Routes: Travel and Translation in the Late Twentieth Century. Cambridge: Harvard University Press, p. 188-219.

FOUCAULT, M. (2000). Microfísica do poder. Organização e tradução de Roberto Machado. Rio de Janeiro: Edições Graal.

GARCÍA CANCLINI, Néstor. (2005). Diferentes, desiguais e desconectados: mapas da interculturalidade. Tradução de Luiz Sérgio Henriques. Rio de Janeiro: Ed. UFRJ.

GELL, Alfred. (1998). Art and Agency: An Anthropological Theory. Oxford: Clarendon.

GONÇALVES, J. R. S. (2002). A Retórica da Perda: os discursos do patrimônio cultural no Brasil. Rio de Janeiro: Editora UFRJ; Iphan.

GRÜNEWALD, Rodrigo de A. (1993). "Regime de Índio” e Faccionalismo: os Atikum da Serra do Umã. Dissertação de Mestrado. PPGAS / MN / UFRJ.

Rodrigo de A. (2001). Os índios do descobrimento: tradição e turismo. Rio de Janeiro: Contra Capa Livraria.

, Rodrigo de A. (2005). As Múltiplas Incertezas do Toré. In: Toré: Regime

Encantado dos Índios do Nordeste. Org. Rodrigo de Azeredo Grünewald, Ed. Massangana (FUNDAJ). Recife.

HANDLER, R. \& LINNEKIN, J. (1984). Tradition, Genuine or Spurious. In: Journal of American Folklore, Vol. 97, nº 385.

HANNERZ, U. (1997). Fluxos, Fronteiras, Híbridos: Palavras-Chave da Antropologia Transnacional. In Mana3 (1): 7-39.

LATOUR, Bruno. (1994). We have never been modern. Tr. C. Porter. Cambridge, MA: Harvard University Press.

, Bruno. (2005). Reassembling the social: an introduction to actor-network theory.

Oxford: Oxford University Press.

MARCUS, George. (1998). Multi Situated Ethnography. In: Ethnography through Thick \& Thin. Princeton: Princeton University Press.

MARCUS, George E. \& FISCHER, Michael M. J. (1986). Anthropology as Cultural Critique: An Experimental Moment in the Human Sciences. Chicago, The University of Chicago Press.

MATTA, Priscila Matta. (2005). Dois Elos da Mesma Corrente: Uma Etnografia da Corrida do Umbu e da Penitência entre os Pankararu. Universidade de São Paulo, Faculdade de Filosofia, Letras e Ciências Humanas. Programa de Pós-Graduação em Antropologia Social. São Paulo-SP.

MOTA, Clarice Novaes da. (2005). Performance e Significações do Toré: o caso dos Xocó e KaririXocó. In: Toré: Regime Encantado dos Índios do Nordeste. Org. Rodrigo de Azeredo Grünewald, Ed. Massangana (FUNDAJ). Recife.

Clarice Novaes da. (2008). Ser indígena no Brasil contemporâneo: novos rumos para um velho dilema. In: Cienc. Cult., São Paulo, v. 60, n. 4.

MOTA, C.N. da \& BARROS, J.F.P. (2002). O Complexo da Jurema: Representações e Drama Social Negro-indígena. In: As muitas faces da Jurema: de espécie botânica à divindade afroindígena. MOTA, C.N. da \& ALBUQUERQUE, V.P de (org.). Recife: Bagaço.

NASCIMENTO, M. T. de S. (sem data). A jurema: das ramas até o tronco. Ensaio sobre algumas categorias de classificação religiosa. Artigo digitado. Salvador, BA.

OLIVEIRA, João Pacheco de. (1988). "O Nosso Governo": Os Ticuna e o Regime Tutelar. São Paulo: Marco Zero. 
, João Pacheco de. (1999a). Uma Etnologia dos 'Índios Misturados'? Situação Colonial, Territorialização e Fluxos Culturais. In: A Viagem de Volta. Etnicidade, Política e Reelaboração Cultural no Nordeste Indígena. Rio de Janeiro, Contra Capa. p. 11-36.

UFRJ. João Pacheco de. (1999b). Ensaios em antropologia histórica. Rio de janeiro: Editora

PALITOT, Estevão Martins. (2005). Os Potiguara da Baía da Traição e Monte-Mór: História, Etnicidade e Cultura. Dissertação de Mestrado (PPGS) Universidade Federal da Paraíba. João Pessoa.

PRICE, Sally. (2000). Arte Primitiva em Centros Civilizados. Tradução de Inês Alfano; revisão técnica de José Reginaldo Santos Gonçalves. Rio de Janeiro: Editora UFRJ.

SANDRONI, Carlos; VILAR, Gustavo; ACSELRAD, Maria. (2005). Torés Pankararu ontem e hoje. In: Toré: Regime Encantado dos Índios do Nordeste. Org. Rodrigo de Azeredo Grünewald, Ed. Massangana (FUNDAJ). Recife.

SOUZA LIMA, Antonio Carlos (1995). Um Grande Cerco de Paz. Poder tutelar, indianidade e formação do Estado no Brasil. Petrópolis, Vozes.

TAUSSIG, M. (1993). Mimesis and Alterity: A Particular History of the Senses. New York: Routledge.

VALLE, Carlos Guilherme Otaviano do. (1999). Experiência e semântica entre os Tremembé do Ceará. In: A Viagem de Volta. Etnicidade, Política e Reelaboração Cultural no Nordeste Indígena. Rio de Janeiro, Contra Capa. 